\title{
Interrelated factor demand with nonconvex adjustment costs: a note
}

Citation for published version (APA):

Letterie, W. A., Nilsen, O. A., \& Pfann, G. A. (2008). Interrelated factor demand with nonconvex adjustment costs: a note. METEOR, Maastricht University School of Business and Economics. METEOR Research Memorandum No. 002 https://doi.org/10.26481/umamet.2008002

Document status and date:

Published: 01/01/2008

DOI:

10.26481/umamet.2008002

Document Version:

Publisher's PDF, also known as Version of record

\section{Please check the document version of this publication:}

- A submitted manuscript is the version of the article upon submission and before peer-review. There can be important differences between the submitted version and the official published version of record.

People interested in the research are advised to contact the author for the final version of the publication, or visit the DOI to the publisher's website.

- The final author version and the galley proof are versions of the publication after peer review.

- The final published version features the final layout of the paper including the volume, issue and page numbers.

Link to publication

\footnotetext{
General rights rights.

- You may freely distribute the URL identifying the publication in the public portal. please follow below link for the End User Agreement:

www.umlib.nl/taverne-license

Take down policy

If you believe that this document breaches copyright please contact us at:

repository@maastrichtuniversity.nl

providing details and we will investigate your claim.
}

Copyright and moral rights for the publications made accessible in the public portal are retained by the authors and/or other copyright owners and it is a condition of accessing publications that users recognise and abide by the legal requirements associated with these

- Users may download and print one copy of any publication from the public portal for the purpose of private study or research.

- You may not further distribute the material or use it for any profit-making activity or commercial gain

If the publication is distributed under the terms of Article $25 \mathrm{fa}$ of the Dutch Copyright Act, indicated by the "Taverne" license above, 
Wilko Letterie, Øivind A. Nilsen, Gerard Pfann

Interrelated Factor Demand with Nonconvex Adjustment Costs: a Note

$\mathrm{RM} / 08 / 002$

JEL code: D92, E22, E24, J23, L60

\section{METEबrR}

Maastricht research school of Economics

of TEchnology and ORganizations

Universiteit Maastricht

Faculty of Economics and Business Administration P.O. Box 616

NL - 6200 MD Maastricht

phone : :++31433883830

fax : ++31433884873 


\title{
Interrelated Factor Demand with Nonconvex Adjustment Costs: A Note
}

\author{
Wilko Letterie* \\ Øivind A. Nilsen ${ }^{* *}$ \\ Gerard Pfann $^{* * *}$
}

February 2008

* Corresponding author; Maastricht University, Faculty of Economics and Business Administration, Department of Organization and Strategy, P.O. Box 616, 6200 MD Maastricht, The Netherlands, Email: w.letterie@os.unimaas.n]; Tel: +31 43 3883645; Fax: +31 433884893.

** Norwegian School of Economics and Business Administration, Department of Economics, Hellevn. 30, NO-5045 Bergen, Norway; Email: oivind.nilsen@ nhh.no.

*** Maastricht University, Faculty of Economics and Business Administration, Department of Econometrics, P.O. Box 616, 6200 MD Maastricht, The Netherlands, Email: g.pfann@ke.unimaas.n. 


\begin{abstract}
:
In this paper we develop a model to describe a firm's demand for two production factors which is subject to the presence of nonconvex adjustment costs. In our model simultaneous adjustment of these two production factors may either increase or decrease the total costs incurred by the firm. The magnitude of this change in total costs ultimately determines the likelihood of joint adjustment. We also show that the importance of interrelation is suppressed by large fixed costs.
\end{abstract}

JEL Codes: D92, E22, E24, J23, L60

Key Words: Factor Demand, Interrelation, Nonconvex Adjustment Costs 


\section{Introduction}

This paper presents a dynamic model of interrelated factor demand under uncertainty with nonconvex adjustment costs. The models' solution in closed form reveals that the probability of simultaneous adjustment (synchronization) depends largely on the interrelation and especially on the question whether or not interrelation adds to the costs of changing inputs or lowers those costs. The answer to that question will vary from project to project.

Recent empirical studies by Sakellaris [9] and Letterie, Pfann and Polder [6] have revealed that in the context of lumpy adjustment the dynamics of labour and capital demand are interrelated. In particular, these papers have shown that at the micro level investment and labour spikes are synchronized to a large extent. Contreras [3] investigates interrelation for a glass mould firm using simulated moments and calibration. He finds that it is more costly for the firm to adjust capital and employment at the same time rather than sequentially. Nadiri and Rosen [8] and Merz and Yashiv [7] have studied the topic of interrelation at the macro level in a traditional framework without nonconvex costs of adjustment. In this paper we develop a theoretical model in which a firm decides about the optimal level of two production factors. Adjustments of these factors involve nonconvex adjustment costs. We refer to these factors as capital and labour but it can also describe the behaviour of a firm deciding about any two different input types (for instance R\&D and natural resources).

Our model deviates from work by Eberly and Van Mieghem [5], Dixit [4] and Bloom [2]. We allow for the possibility that adjustment costs decrease or increase when the firm decides to adjust two factors simultaneously. In order to derive the closed form solution we will use the similar continuous time framework advanced by Abel and Eberly [1]. The closed form solution of the firm's optimization problem is important since it will allow us to investigate under which conditions interrelation is relevant. 
The paper proceeds as follows. In section 1 we develop the model. In section 2 we argue that large fixed costs of adjustment dampen the role played by the cost of interrelation. Finally, section 3 concludes.

\section{The model}

Consider a firm that employs two production factors (capital $K_{t}$ and labour $L_{t}$ in year $t$ ) to produce a non-storable output. The firm's management maximizes $V($.$) denoting the present discounted value$ of the revenue resulting from its business operations. The objective function is given by the value of the firm represented by

$$
V\left(K_{t}, L_{t}, \varepsilon_{t}\right)=\max _{I_{t+s}, H_{t+s}} \int_{0}^{\infty} E_{t}\left\{\pi_{s} \cdot e^{-\beta s} d s\right\}
$$

The discount rate is given by $\beta$ with $0<\beta<1$. The operating profit of the firm at year $t$ is equal to $\pi_{t}=F\left(K_{t}, L_{t}, \varepsilon_{t}\right)-w_{t} L_{t}-C\left(I_{t}, K_{t}, H_{t}, L_{t}\right)$. The variable $w_{t}$ denotes the wage paid by the firm to a full time worker. Investment and hiring (or firing) are denoted by $I_{t}$ and $H_{t}$ respectively. Sales are given

by the expression $F\left(K_{t}, L_{t}, \varepsilon_{t}\right)$ where the term $\varepsilon_{t}$ represents a variable capturing randomness in technology or stochastic behaviour of the demand conditions the firm is facing. The stochastic term $\varepsilon_{t}$ evolves according to

$d \varepsilon_{t}=\mu\left(\varepsilon_{t}\right)+\sigma\left(\varepsilon_{t}\right) \cdot d z$

where $d z$ is a standard Wiener process.

When adjusting the stock of capital or the number of workers the firm incurs adjustment costs defined as: 


$$
\begin{aligned}
& C\left(I_{t}, K_{t}, H_{t}, L_{t}\right)=\left[p_{t}^{I+} I_{t} \cdot \mathrm{I}\left(I_{t}>0\right)+p_{t}^{I-} I_{t} \cdot \mathrm{I}\left(I_{t}<0\right)+\alpha^{K}+\frac{b^{k}}{2}\left(\frac{I_{t}}{K_{t}}\right)^{2} \cdot K_{t}\right] \cdot \mathrm{I}\left(I_{t} \neq 0\right)+ \\
& +\left[p_{t}^{H+} H_{t} \cdot \mathrm{I}\left(H_{t}>0\right)-p_{t}^{H-} H_{t} \cdot \mathrm{I}\left(H_{t}<0\right)+\alpha^{L}+\frac{b^{L}}{2}\left(\frac{H_{t}}{L_{t}}\right)^{2} \cdot L_{t}\right] \cdot \mathrm{I}\left(H_{t} \neq 0\right)+ \\
& +\alpha^{K L} \cdot \mathrm{I}\left(I_{t} \neq 0\right) \cdot \mathrm{I}\left(H_{t} \neq 0\right)
\end{aligned}
$$

In the adjustment cost function $C\left(I_{t}, K_{t}, H_{t}, L_{t}\right)$ the indicator function $\mathrm{I}($.$) assumes the value 1$ if the condition in brackets is satisfied and equals zero otherwise. The purchase price of capital is given by $p_{t}^{I+}$. In case the firm sells capital we assume that the price received for one unit of capital equals $p_{t}^{I-}$. Due to irreversibility of investment decisions $p_{t}^{I+}>p_{t}^{I-}$. Rinear adjustment costs with respect to hiring and firing are denoted by $p_{t}^{H+}$ when $H_{t}>0$ and $p_{t}^{H-}$ when $H_{t}<0$. The convex costs are represented by conventional quadratic functions in $\frac{I_{t}}{K_{t}}$ and $\frac{H_{t}}{L_{t}} \cdot$ The fixed costs associated with adjusting capital and labour are represented by $\alpha^{K}$ and $\alpha^{L}$ respectively and we assume that both parameters are nonnegative and do not depend on whether $I_{t}$ and $H_{t}$ are positive or negative. Fixed costs can be a result of the firm's production processes being disrupted when

${ }^{1}$ Note that the actual investment costs are incorporated in the adjustment costs function in its linear part.

${ }^{2}$ It is straightforward to extend this adjustment cost function with a term capturing convex costs of interrelation like $\gamma \cdot\left(\frac{I}{K} \cdot \frac{H}{L}\right) \cdot K^{\phi} \cdot L^{1-\phi}$ where $0<\phi<1$. We abstract from this possibility to facilitate notation and hence enhance readability of the paper, but the extension is available upon request. We note that in the figures presented later in this paper the area where simultaneous adjustment $(I \neq 0$ and $H \neq 0)$ takes place becomes defined by curved boundaries rather than straight lines if $\gamma \neq 0$. 
adjustment of capital or labour takes place. Alternatively, the firm's management may have to spend costly time guiding these organizational changes. We also assume that if the firm adjusts labour or capital, then the adjustment costs of the other factor demand component are affected. The term $\alpha^{K L}$ is positive if simultaneous adjustment of capital and labour forces the management to spend additional time and effort on the joint adjustment, or that the adjustment causes a more severe production interruption compared to when capital or labour adjustments are undertaken at separate points in time. On the other hand, the expression $\alpha^{K L}$ is negative if the firm's managers save time or if the firm can save on costs of disruption when adjusting the factors jointly.

The firm decides upon the optimal size of the capital stock, $K_{t}$, by setting investment $I_{t}$ at the appropriate level. Since capital depreciates at rate $\delta^{K}$, the stock of capital evolves according to the law of motion

$$
d K_{t}=\left(I_{t}-\delta^{K} K_{t}\right) \cdot d t
$$

Simultaneously, the firm determines the optimal value for the number of workers $L_{t}$ by choosing the desired and hence optimal level of hiring or firing denoted by $H_{t}$. The amount of labour evolves according to $d L_{t}=\left(H_{t}-\delta^{L} L_{t}\right) \cdot d t$

where $\delta^{L}$ measures the autonomous quit rate of workers.

To obtain the optimal values for $I_{t}$ and $H_{t}$ eq. (1) can be optimized with respect to these decision variables subject to the laws of motion governing the dynamics of capital, labour and $\varepsilon_{t}$ as given by eqs. (4), (5) and (2). Before proceeding we note that the variables $\lambda_{t}^{K}$ and $\lambda_{t}^{L}$ are 
conventional marginal Q variables ${ }^{3}$ Abel and Eberly [1] show that the optimal decisions within this framework can be solved by

$$
\max _{I_{t}, H_{t}}\left[\lambda_{t}^{K} I_{t}+\lambda_{t}^{L} H_{t}-C\left(I_{t}, K_{t}, H_{t}, L_{t}\right)\right] .
$$

The optimal amount of investment and hiring or firing are ${ }^{4}$

$$
\begin{aligned}
& \frac{I_{t}}{K_{t}}=\left(\frac{\lambda_{t}^{K}-p_{t}^{I}}{b^{K}}\right) \\
& \frac{H_{t}}{L_{t}}=\left(\frac{\lambda_{t}^{L}-p_{t}^{H}}{b^{L}}\right)
\end{aligned}
$$

Due to the presence of fixed costs of adjustment the firm will not always follow the decision rules presented in eq. (7). Sometimes it may be optimal to abstain from adjusting capital and or adjusting labour. The threshold equation determining whether to change the stock of capital and or to adjust labour becomes

$$
\lambda_{t}^{K} I_{t}+\lambda_{t}^{L} H_{t} \geq C\left(I_{t}, K_{t}, H_{t}, L_{t}\right)
$$

The left hand side of (8) measures the expected benefits of changing capital and or labour, whereas the right hand side denotes the cost associated with the firm's decisions. It can be shown that eq. (8) holds if

$$
\begin{array}{r}
\frac{1}{2 b^{K}}\left(\lambda_{t}^{K}-p_{t}^{I}\right)^{2} K_{t} \cdot \mathrm{I}\left(I_{t} \neq 0\right)+\frac{1}{2 b^{L}}\left(\lambda_{t}^{L}-p_{t}^{H}\right)^{2} L_{t} \cdot \mathrm{I}\left(H_{t} \neq 0\right) \geq \\
\alpha^{K} \cdot \mathrm{I}\left(I_{t} \neq 0\right)+\alpha^{L} \cdot \mathrm{I}\left(H_{t} \neq 0\right)+\alpha^{K L} \cdot \mathrm{I}\left(I_{t} \neq 0\right) \cdot \mathrm{I}\left(H_{t} \neq 0\right)
\end{array}
$$

${ }^{3}$ In fact $\lambda_{t}^{K}=\int_{0}^{\infty} E_{t}\left(\frac{\partial \pi_{t}}{\partial K_{t}}\right) e^{-\left(\beta+\delta^{K}\right)} d s$ and $\lambda_{t}^{L}=\int_{0}^{\infty} E_{t}\left(\frac{\partial \pi_{t}}{\partial L_{t}}\right) e^{-\left(\beta+\delta^{L}\right)} d s$

${ }^{4}$ The first order conditions for investment and labour adjustment are $\lambda_{t}^{K}-p_{t}^{I+} \cdot \mathrm{I}\left(I_{t}>0\right)-p_{t}^{I-} \cdot \mathrm{I}\left(I_{t}<0\right)-b^{K}\left(\frac{I_{t}}{K_{t}}\right)=0$ and $\lambda_{t}^{L}-p_{t}^{H+} \cdot \mathrm{I}\left(H_{t}>0\right)+p_{t}^{H-} \cdot \mathrm{I}\left(H_{t}<0\right)-b^{L}\left(\frac{H_{t}}{L_{t}}\right)=0$ respectively.

In eq. (7) $p_{t}^{I} \equiv p_{t}^{I+} \cdot \mathrm{I}\left(I_{t}>0\right)+p_{t}^{I-} \cdot \mathrm{I}\left(I_{t}<0\right)$ and $p_{t}^{H} \equiv p_{t}^{H+} \cdot \mathrm{I}\left(H_{t}>0\right)-p_{t}^{H-} \cdot \mathrm{I}\left(H_{t}<0\right)$. 
To solve the optimization problem of the firm we derive the conditions necessary for various adjustment decisions.

1a. Simultaneous change increases the cost of adjustment: $\alpha^{K L}>0$

The firm regards adjusting the stock of capital goods to be desirable if $\frac{1}{2 b^{K}}\left(\lambda_{t}^{K}-p_{t}^{I}\right)^{2} K_{t} \geq \alpha^{K}$. Hence, a necessary condition for changing the amount of capital is $\left|\lambda_{t}^{K}-p_{t}^{I}\right|>\sqrt{\frac{2 b^{K} \alpha^{K}}{K_{t}}} \equiv A^{K}$

A similar necessary condition for hiring or firing workers is $\frac{1}{2 b^{L}}\left(\lambda_{t}^{L}-p_{t}^{H}\right)^{2} L_{t} \geq \alpha^{L}$ implying $\left|\lambda_{t}^{L}-p_{t}^{H}\right|>\sqrt{\frac{2 b^{L} \alpha^{L}}{L_{t}}} \equiv A^{L}$

Eqs. (10) and (11) show that if the net benefits of adjusting capital and labour do not exceed a certain minimum threshold, the management will decide to abstain adjusting. These two thresholds are caused by the existence of the fixed adjustment costs.

Consider now the case where both necessary conditions to adjust capital and labour are satisfied as given in eqs. (10) and (11). Hence, the firm has an incentive to adjust at least one factor of production. However, due to the cost of interrelation the firm may need to select adjusting only one factor to maximise its objective function. It is optimal to adjust the number of workers rather than the stock of capital if

$$
\begin{aligned}
& \frac{1}{2 b^{L}}\left(\lambda_{t}^{L}-p_{t}^{H}\right)^{2} L_{t}-\alpha^{L} \geq \frac{1}{2 b^{K}}\left(\lambda_{t}^{K}-p_{t}^{I}\right)^{2} K_{t}-\alpha^{K} . \text { This holds when } \\
& \left(\lambda_{t}^{L}-p_{t}^{H}\right)^{2} \geq \frac{b^{L}}{b^{K}} \frac{K_{t}}{L_{t}}\left(\lambda_{t}^{K}-p_{t}^{I}\right)^{2}+\frac{2 b^{L}}{L_{t}}\left[\alpha^{L}-\alpha^{K}\right]
\end{aligned}
$$

We can also rewrite this condition as: 


$$
\left(\lambda_{t}^{L}-p_{t}^{H}\right)^{2} \geq \frac{2 b^{L}}{L_{t}} \alpha^{L}+\left[\frac{b^{L}}{b^{K}} \frac{K_{t}}{L_{t}}\left(\lambda_{t}^{K}-p_{t}^{I}\right)^{2}-\frac{2 b^{L}}{L_{t}} \alpha^{K}\right]
$$

The first term on the RHS of this expression is positive given our assumptions about the adjustment costs parameters and the content in the squared bracket is also positive according to eq. (10). Thus, the sum of the two terms is positive. Hence it is optimal to adjust labour rather than capital if

$$
\left|\lambda_{t}^{L}-p_{t}^{H}\right| \geq \sqrt{\frac{b^{L}}{b^{K}} \frac{K_{t}}{L_{t}}\left(\lambda_{t}^{K}-p_{t}^{I}\right)^{2}+\frac{2 b^{L}}{L_{t}}\left[\alpha^{L}-\alpha^{K}\right]}
$$

Under certain conditions it is optimal to adjust only one input factor, because of the cost of interrelation. It is optimal to adjust an additional factor of production if the net benefits associated with that adjustment exceed the fixed costs of that second input ( $\alpha^{K}$ or $\left.\alpha^{L}\right)$ plus the cost of interrelation $\alpha^{K L}>0$. Hence, it is worth also adjusting the stock of capital (given that adjusting labour yields a higher value of the firm if only one input needs to be selected) as soon as

$$
\frac{1}{2 b^{K}}\left(\lambda_{t}^{K}-p_{t}^{I}\right)^{2} K_{t} \geq \alpha^{K}+\alpha^{K L}
$$

Similarly, labour will also be adjusted (given that changing capital yields a higher firm value if only one input is selected) as soon as

$$
\frac{1}{2 b^{L}}\left(\lambda_{t}^{L}-p_{t}^{H}\right)^{2} L_{t} \geq \alpha^{L}+\alpha^{K L}
$$

Hence, the boundaries determining when the firm will adjust both factors of production are

$$
\begin{aligned}
& \left|\lambda_{t}^{K}-p_{t}^{I}\right|>\sqrt{\frac{2 b^{K}\left(\alpha^{K}+\alpha^{K L}\right)}{K_{t}}} \equiv B^{K} \\
& \left|\lambda_{t}^{L}-p_{t}^{H}\right|>\sqrt{\frac{2 b^{L}\left(\alpha^{L}+\alpha^{K L}\right)}{L_{t}}} \equiv B^{L}
\end{aligned}
$$


The analysis of firm level capital and labour demand decisions is summarized in figure 1 . The curved boundary in figure 1 crosses the rectangular areas at $A^{L}=A^{K}$ and $B^{L}=B^{K}$. $^{5}$ The firm only adjusts the two factors of production in the area depicted in the upper right corner of the figure. This area moves further away from the origin if $\alpha^{K L}$ increases lowering the likelihood of simultaneous adjustment. In fact, higher interrelated adjustment costs, $\alpha^{K L}$, increase the distance between $A^{K}$ and $B^{K}$, and between $A^{L}$ and $B^{L}$. This means that the net benefit of changes, $\lambda_{t}^{K}-p_{t}^{I}$ and $\lambda_{t}^{L}-p_{t}^{H}$, need to be sufficiently large for the firm to choose to change both input factors simultaneously.

$$
* * * \text { Insert figure } 1 \text { about here } * * *
$$

\section{1b. Simultaneous adjustment decreases cost of adjustment: $\alpha^{K L} \leq 0$}

If $\alpha^{K L} \leq 0$ firms actually benefit from adjusting both input factors simultaneously. The above analysis can be applied to a large extent here as well. The main difference is that the choice between investment or labour adjustment as presented below eq. (12) has become irrelevant in this case. This is due to the fact that the thresholds $B^{L}$ and $B^{K}$ are smaller than $A^{L}$ and $A^{K}$ respectively if

${ }^{5}$ This curve corresponding to the right hand side of eq. (13) is concave if $\alpha^{K}>\alpha^{L}$. Hence in figure 1 we depict the case $\alpha^{K}>\alpha^{L}$ where the curved boundary crosses the horizontal axis (i.e. where $\left.\left|\lambda_{t}^{L}-p_{t}^{H}\right|=0\right)$ at $x_{k} \equiv \sqrt{\frac{2 b^{K}\left(\alpha^{K}-\alpha^{L}\right)}{K_{t}}}$. If $\alpha^{L}>\alpha^{K}$ the right hand side of (13) is convex and the curved boundary crosses the vertical axis (i.e. where $\left|\lambda_{t}^{K}-p_{t}^{I}\right|=0$ ) at $y_{L} \equiv \sqrt{\frac{2 b^{L}\left(\alpha^{L}-\alpha^{K}\right)}{L_{t}}}$. Note that if $\alpha^{L}=\alpha^{K}$ the boundary determining whether to invest or adjust labour becomes a straight line. 
$\alpha^{K L} \leq 0$ (also see eqs. 10, 11 and 15). Figure 2 indicates that if the firm incurs lower adjustment costs because of simultaneous adjustment the incidence of this event becomes more likely. If $\alpha^{K L}$ decreases then the area representing the situation that the firm changes both labour and capital moves in the direction of the origin of the figure, meaning that joint adjustment becomes more likely. If $\alpha^{L}+\alpha^{K L} \leq 0$, the horizontal threshold at $B^{L}$ will lie at the horizontal axis of figure 2 . This means if the firm invests it will also change its labour force, i.e. the area $I \neq 0, H=0$ disappears. If $\alpha^{K}+\alpha^{K L} \leq 0$ then the firm will always invest as soon as it alters its number of workers because the vertical threshold at $B^{K}$ will hit the vertical axis of the figure and the area $I=0, H \neq 0$ vanishes. If both conditions $\alpha^{K}+\alpha^{K L} \leq 0$ and $\alpha^{L}+\alpha^{K L} \leq 0$ hold then the firm will always change the two factors of production at the same time.

$* * *$ Insert figure 2 about here $* * *$

\section{Large fixed costs dampen importance of interrelation}

It is worth noting that if the fixed costs of adjustment $\alpha^{K}$ and $\alpha^{L}$ increase, the interrelated cost measured by $\alpha^{K L}$ plays a decreasing role in determining the optimal decisions of the firm. It is straightforward to show that $\frac{\partial\left|B^{i}-A^{i}\right|}{\partial \alpha^{i}}<0$ and $\lim _{\alpha^{i} \rightarrow \infty}\left|B^{i}-A^{i}\right|=0$ for $i \in\{K, L\}$. This means that in figures 1 and 2 the area where the firm completely abstains from adjusting $(I=0$ and $H=0)$ and the area where both factors are adjusted simultaneously $(I \neq 0$ and $H \neq 0)$ tend to move closer to each other as the fixed costs become larger. Hence, large fixed costs will suppress the effect of interrelation. In figure 3 we depict the case where the fixed costs of capital are much larger than the fixed costs of labour. In the area where only one factor is adjusted the event of joint adjustment is sensitive to small changes in the shadow value of capital but relatively unresponsive to changes in the shadow value of labour. 
*** Insert figure 3 about here $* * *$

\section{Conclusion}

If it is costly to adjust two factors of production at the same time a firm has an incentive to conduct a one at a time policy: adjust only one factor. Recent empirical studies indicate that large adjustments tend to be synchronized in some data sets, and in others they are not. In this paper we show that this feature of the data may be consistent with the hypothesis that joint adjustment increases or reduces the overall costs of adjustment (i.e. $\alpha^{K L}>0$ or $\alpha^{K L} \leq 0$ ). We also found that when fixed costs of adjustment are large then the role played by the cost of interrelation may be minor. Hence, synchronization may occur because large fixed costs dampen the relative importance of interrelation. Moreover, the dynamics of factor demand are also determined by the shadow values (i.e. $\lambda_{t}^{K}-p_{t}^{I}$ and $\lambda_{t}^{L}-p_{t}^{H}$ ). If these shadow values are positively correlated then joint adjustment is likely.

Demand for both factors is non-zero if $\left|\lambda_{t}^{K}-p_{t}^{I}\right|$ and $\left|\lambda_{t}^{L}-p_{t}^{H}\right|$ are high. For instance, a high positive demand shock may increase $\lambda_{t}^{K}$ and $\lambda_{t}^{L}$ simultaneously and hence provide the firm an incentive to expand the scale of the firm by increasing both factors of production. On the other hand, a firm may be increasing one input and decreasing the other input at the same time if shadow values move in opposite directions. Such a situation may arise due to a policy change affecting the relative price of the two factors of production or due to a technology shock changing the optimal share of the inputs to produce a certain level of output. But whether the adjustments of the input factors are made simultaneously or sequentially depends on the size of the interrelated adjustment costs. 


\section{References}

[1] A.B. Abel, J.C. Eberly, A unified model of investment under uncertainty, American Economic Review 84, (1994), 1369-1384.

[2] N. Bloom, The impact of uncertainty shocks, NBER working paper No. 13385, (2007).

[3] J.M. Contreras, Essays on factor adjustment dynamics. PhD Thesis, University of Maryland, Department of Economics, (2006).

[4] A. Dixit, Investment and employment dynamics in the short and the long run, Oxford Economic Papers 49, (1997), 1-20.

[5] J.C. Eberly, J.A. van Mieghem, Multi-factor dynamic investment under uncertainty, Journal of Economic Theory 75, (1997), 345-387.

[6] W.A. Letterie, G.A. Pfann, J.M. Polder, Factor adjustment spikes and interrelation: an empirical investigation, Economics Letters 85, (2004), 145-150.

[7] M. Merz, E. Yashiv, Labor and the value of the firm, American Economic Review 97, (2007), 1419-1431.

[8] M.I. Nadiri, S. Rosen, Interrelated factor demand functions, American Economic Review 59, (1969), 457-471.

[9] P. Sakellaris, Patterns of plant adjustment, Journal of Monetary Economics 51, (2004), 425-450. 
Figure 1: Simultaneous change increases adjustment costs: $\alpha^{K L}>0$

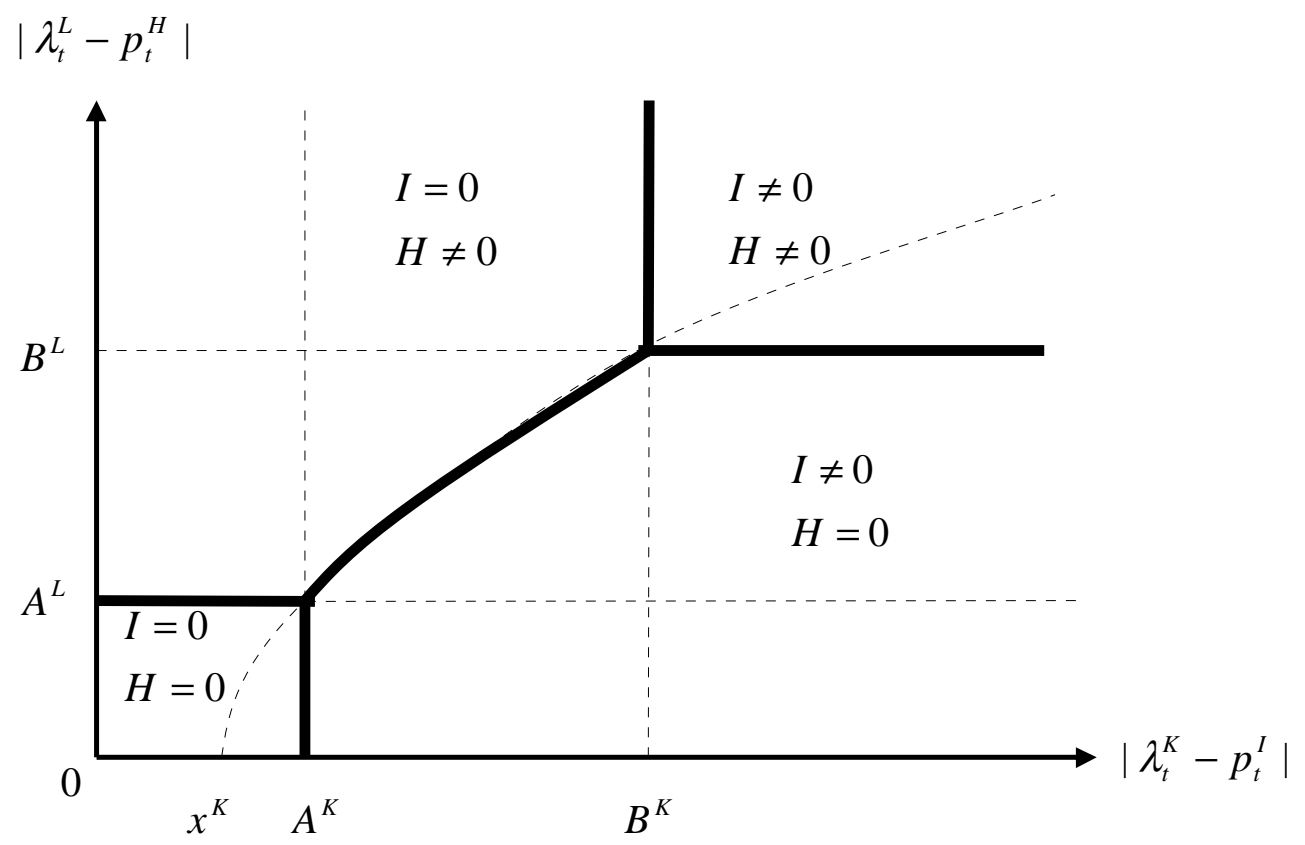

Notes:

See the main text for definitions of $x^{K}, A^{K}, B^{K}, A^{L}$ and $B^{L}$.

Parameters satisfy $\alpha^{L}+\alpha^{K L}>0 ; \alpha^{K}+\alpha^{K L}>0$ 
Figure 2: Simultaneous change reduces adjustment costs: $\alpha^{K L}<0$.

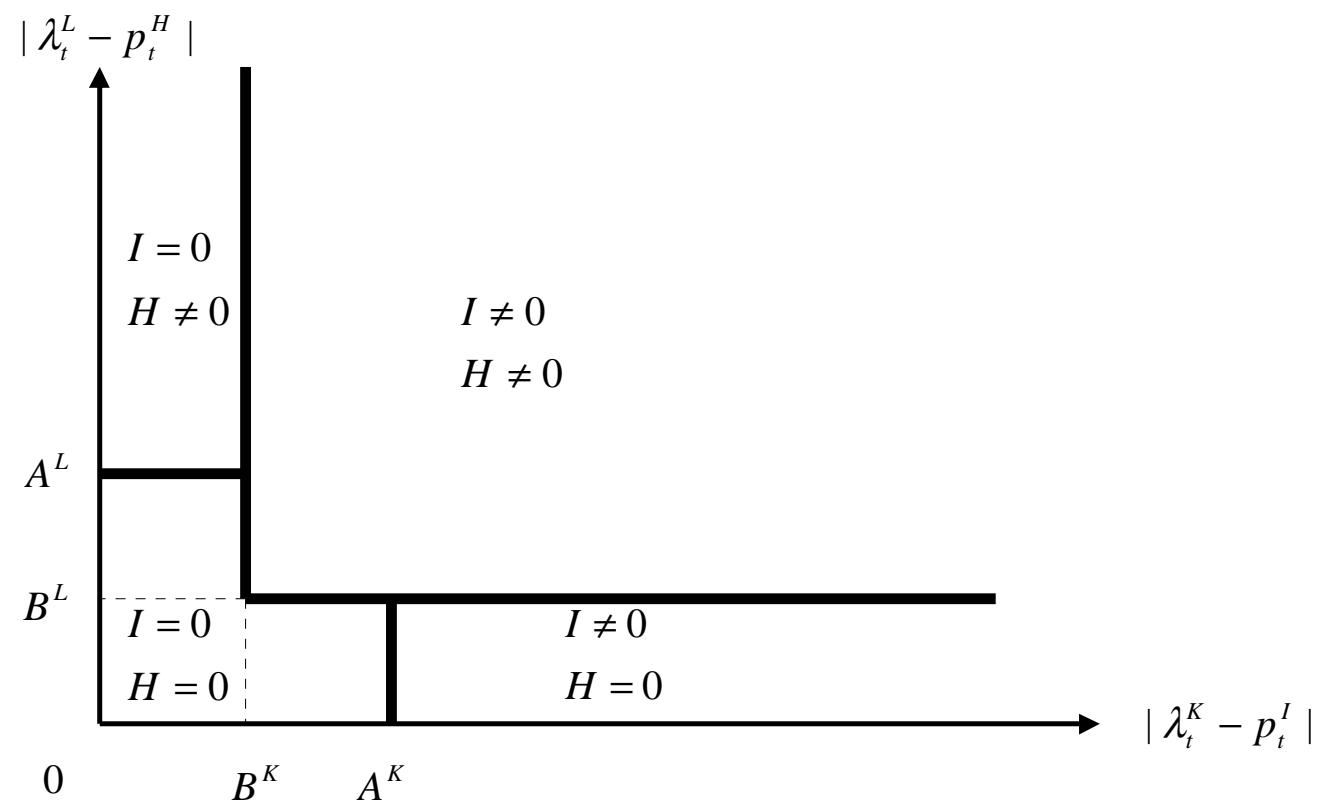

Notes: See notes of Figure 1. 
Figure 3: Fixed adjustment costs of capital are much larger than fixed adjustment costs of labour: $\alpha^{K}>\alpha^{L}$.

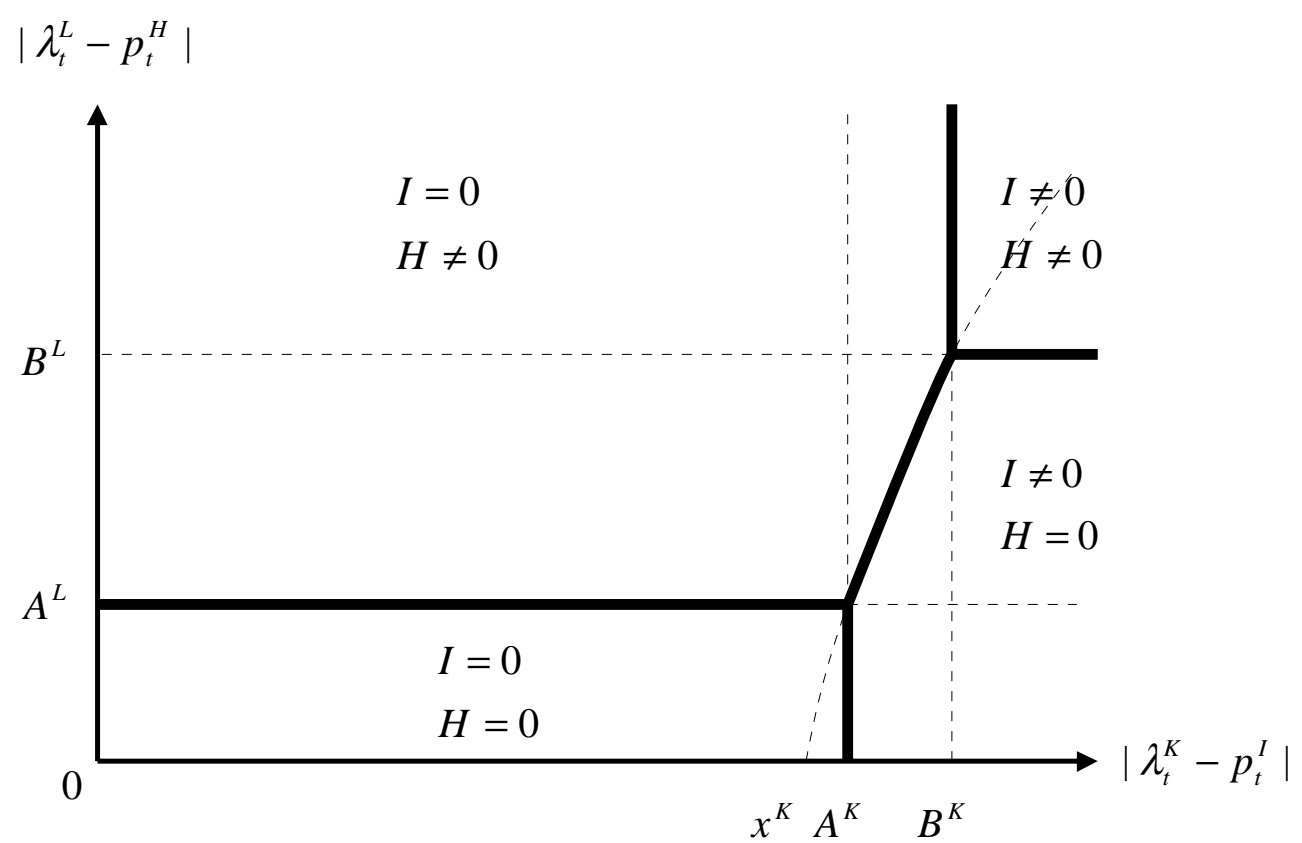

Notes: See notes of Figure1 and $\alpha^{K L}>0$. 